\title{
CFD MODELLING OF AN ENTIRE SYNCHRONOUS GENERATOR FOR IMPROVED THERMAL MANAGEMENT
}

\author{
P.H. Connor*, S.J. Pickering*, C. Gerada ${ }^{\dagger}$, C.N. Eastwick*, C. Micallef^, C. Tighe ${ }^{+}$ \\ ${ }^{\star}$ Division of Energy and Sustainability, University of Nottingham, University Park, Nottingham, NG7 2RD, UK \\ eaxpc@nottingham.ac.uk \\ $广$ Division of Electrical Systems and Optics, University of Nottingham, University Park, Nottingham, NG7 2RD, UK \\ $\wedge$ Department of Mechanical Engineering, Faculty of Engineering, University of Malta \\ ${ }^{+}$Cummins Generator Technologies, Stamford, PE9 2NB, UK
}

Keywords: Generator, Airflow, Thermal, CFD, Efficiency

\begin{abstract}
This paper is the first in a series dedicated to investigating the airflow and thermal management of electrical machines. Due to the temperature dependent resistive losses in the machine's windings, any improvement in cooling provides a direct reduction in losses and an increase in efficiency. This paper focuses on the airflow which is intrinsically linked to the thermal behaviour of the machine as well as the windage power consumed to drive the air through the machine. A full CFD model has been used to analyse the airflow around all major components of the machine. Results have been experimentally validated and investigated. At synchronous speed the experimentally tested mass flow rate and windage torque were under predicted by $4 \%$ and $7 \%$ respectively by the CFD. A break-down of torque by component shows that the fan consumes approximately $87 \%$ of the windage torque.
\end{abstract}

\section{Introduction}

This paper discusses airflow management for a mid-sized four pole synchronous generator in the sub 250kVA range utilising Computational Fluid Dynamics (CFD) modelling and experimental validation.

Electrical machines require cooling due to resistive losses created within the core rotor and stator windings. The windings are electrically insulated but the insulation will severely degrade above a peak temperature for the given insulation class. Adequate cooling must be targeted at key regions to avoid exceeding the maximum permissible temperature. By cooling the windings, temperature dependent resistive losses are reduced which directly improves the machines' efficiency [1-3]. Airflow and thermal management is key to improving the machine's overall efficiency. Thermal aspects in the generator are directly linked to the airflow as the air velocity over a surface directly impacts the local heat transfer. Understanding where cooling is required, improving cooling by tailoring the airflow and reducing airflow in regions where it is not required is key.

Airflow modelling of electrical machines is traditionally carried out by designers using empirical correlations [4, 5]. Empirical relationships are limited to the specific geometries of a given machine [6]. Flow resistance networks in conjunction with 
correlations [7-12] provide an improved modelling technique, but are not able to provide the detail required to accurately predict the important surface heat transfer which dictates the conduction paths within the important solid windings and laminations [6, 13]. Experimental testing of surface heat transfer is expensive and discrete so does not allow a full understanding of the heat transfer at the surfaces [14]. CFD allows the user to predict the airflow throughout the machine to a far finer resolution $[6,15]$. Local velocities may be calculated allowing accurate heat transfer coefficients to be obtained. Using CFD to predict airflow and surface heat transfer has been used an approach in the past [2, 16-19] for generator analysis. However, these investigations have been with 2D or 3D partial geometries. Conduction in solid regions has also been studied but is segregated from the airflow and relies on the mapping of discrete heat transfer coefficients. The novelty of this work is the attention to mesh detail in the airflow case presented here with a view to incorporating full conjugate heat transfer modelling to fully understand both the thermal and airflow properties of the generator in future work within this project.

Within this paper a full $360^{\circ} \mathrm{CFD}$ model of the generator is presented. The exciter, 4-pole-rotor, stator, centrifugal fan and casing are modelled. Details of an experimental rig, used to provide validation for the CFD model, are provided. Aerodynamic losses around specific geometries, such as the fan, are analysed in detail to identify strategies to reduce windage losses.

\section{Experimental Methodology}

A test rig has been commissioned to validate the CFD airflow modelling carried out in this project. The mass flow rate through the machine, measured shaft windage torque, speed and pressure drops across the machine core allow the CFD model to be validated. The testing described here was run with the generator driven at speed but electrically isolated generating no load. This facilitates the measurement of windage loss.

Mass flow rate is measured through the machine. A sealed plenum is created (see Figure 1) around the machine inlet. Air enters the plenum through a calibrated conical inlet (labelled in Figure 1) manufactured according to B.S.848.

A 'Furness Controls FC012' digital manometer is used to obtain the pressure drop over the inlet which is converted to a mass flow rate. Air is exhausted from the generator back into the room (see Figure 1) perpendicular to the inlet to avoid interfering with the intake measurements. The laboratory is maintained at a constant temperature during testing, although heat created during testing is minimal and any reduction in air density due to a temperature increase is considered negligible. The manometer has an accuracy of $\pm 2.5 \%$ and the mass flow rate result has an overall uncertainty of $\pm 2.1 \%$ found using the Kleine McClintock method for uncertainty analysis [20].

Torque and speed measurements are taken from the shaft mounted 'Datum Electronics M420' torque transducer which is situated between the test generator and drive motor (see Figure 1). The results provide the windage power losses. The torque transducer has a manufacturer's supplied accuracy of $\pm 0.135 \%$. Understanding the distribution of viscous and pressure torque 
losses through the machine allows a greater understanding of the airflow, allowing improvements via geometry alterations. The torque measurement provides a total loss including windage, bearing losses and losses due to residual magnetism in the exciter supplying current flow in the main rotor field winding, whilst the CFD predicts the pure aerodynamic windage.

During a 90 minute test it was noted that there is a reduction in torque over the first 5 minutes of operation at full speed due to the grease packed bearings warming and reaching a steady state operating condition.

The mean steady state torque is $66 \%$ of the initial full speed peak torque with a standard deviation of $0.3 \%$. Torque is declared steady-state as the torque further reduces by $1 \%$ over the remaining test time.

The estimated bearing losses are subtracted from the measured torque using the 'SKF' simple 'Estimation of the frictional moment' model [21].

All tests are carried out after this warm-up period. Between changes of shaft speed the bearing torque is stabilised for 1 minute before readings are collected. The machine under test has a synchronous speed of 1500rpm. However, to aid understanding of the behaviour of the components within the generator, and to provide more validation of the CFD modelling, test data is taken for a range of shaft speeds.

Experimental testing is carried out for a variety of cases including with and without grilles over the outlet areas. The CFD model presented does not have grilles modelled over outlets so the experimental results without grilles are used for validation.

\section{CFD Methodology}

The numerical CFD code used in this project is “ANSYS' Fluent version 13.0”[22]. This is a Reynolds Averaged NavierStokes (RANS) solver. The equations are solved within a meshed fluid domain for the airflow simulation.

Firstly, a full $360^{\circ}$ geometry of all the major components in the generator is created in "ANSYS ICEM CFD version 13.0" (ICEM). The $360^{\circ}$ model is required due to the lack of reflective symmetry in some key geometrical features (see Figure 2).

A three dimensional hybrid mesh is then constructed within the domain using "ICEM". Generators prove an interesting challenge to mesh efficiently with geometry scales of $<1 \mathrm{~mm}$ in and around the airgap to open regions of $>100 \mathrm{~mm}$ and for this reason a hybrid mesh utilising hexahedral and tetrahedral elements is employed. Tetrahedral elements are very efficient within large volumes whilst dense hexahedral meshes provide the level of density required in areas of high shear. The airgap between the rotor and stator which is an annular region of the order of a few millimetres is meshed independently using ICEM's hexahedral 'blocking' feature. This allows a consistent mesh density of 10 cells across the airgap to be maintained which is essential for predicting the complex flow within the airgap which are a key driver of heat transfer and also a key component of the windage torque created. This distribution of cells is important to the success of the solution. 
The hybrid mesh used for the simulation described in this paper is 8 million cells. Mesh independence is checked by doubling the mesh size and ensuring that changes in the solution are negligible.

In all cases the flow is assumed to be steady state, turbulent, isothermal and incompressible.

The main model discussed in this report is the machine with the casing, inlets and outlets as boundaries to the model. This assumes at the inlets and outlets are constant pressure over the surface and flow enters the domain normal to the boundary. To validate this assumption, a model including the surrounding room was created. This added just over $10 \%$ additional cells to the model as a cell growth ratio of 1.2 was employed from the machine into the room. Mass flow rate through the machine increased by $3 \%$ and torque increased by $3.5 \%$ when the room was included in the model with respect to the machine-only model. Although slightly more accurate, it is considered that the additional computational resource is not beneficial. Future work will identify the optimum inlet and outlet zone sizes to improve modelling but at the minimal increase in cell count. The assumption at the outlets is reasonable but it is important to understand that the inlet and outlet effects have been simplified.

As the synchronous generator operates at a steady speed a steady-state solution is sought. Shanel [23] found that the significant cost of transient sliding mesh simulations was not worth the minor benefit of monitoring the non-steady pumping effects of the rotor. As the generator is operated without electrical load for the validation tests the assumption of isothermal flow is valid. The rotor speed is at Mach 0.053 and hence the flow is within the incompressible range.

Fluent's Multiple Reference Frame (MRF) or 'Frozen rotor' technique is employed in this model [22] to simulate the relative motion of the rotor and stator. The fluid region is split into two concentric cylinders by an interior surface. The inner fluid region is set to rotate about the fixed rotor geometry at the synchronous speed. The outer fluid region is set to be stationary (see Figure 3). Mixing occurs across the middle interior surface. The benefit of this technique is a more efficient computation time to solution. However the interaction of the rotor poles and stator slots is not resolved as would occur in reality and the pumping effects of the rotor poles are not modelled.

The standard k-epsilon model [22] is used for turbulence modelling within Fluent as it is more stable for rotating simulations [22].

To resolve the boundary layer a wall function is used. The location of the first cell at a wall is determined by the wall function requirement and is indicated by the $\mathrm{y}^{+}$value which is a non dimensional distance required for the first cell from the wall based on the shear stresses at the wall [22].

The 'enhanced' wall function [22] is used for all cases described in this paper, this allows a wall function to be enabled in regions of relatively coarse mesh whilst enabling a finer mesh to predict the shear behaviour in the boundary layer of the rotating components. For instance in the airgap the geometry scale and complexity determines that the cell sizing must be far 
smaller than the standard wall function [22] would require. The enhanced wall function automatically assigns the method for resolving the boundary based on the $\mathrm{y}^{+}$value. At low $\mathrm{y}^{+}$values of $\sim 1$ the boundary layer is resolved to the viscous sublayer. At values $\mathrm{y}^{+}<11.225$ a wall function is used to compute turbulent region which is particularly valid for $30<\mathrm{y}^{+}<60$. At values $3<\mathrm{y}^{+}<10$ the linear laminar logarithmic turbulent laws are blended [22].

The PC running the simulation is a $3 \mathrm{GHz}$ Intel Quad core CPU with 16GB RAM running the Windows 7 64-bit operating system. A converged steady-state solution is run in around 12 hours.

Boundary conditions are essential to the success of a CFD simulation. Wall boundaries are used to represent most surfaces in the model. Walls in contact with rotating fluid zones are set stationary with respect to the adjoining fluid zone. Pressure inlets and outlets are used to represent the inlets and outlets respectively (see Figure 2). There are 2 inlets and 4 outlets from the machine with reflective symmetry about the vertical plane in the axial direction (see Figure 2). Fluid motion through the machine is driven by the rotation of the fan surfaces.

Several geometrical simplifications are employed within the CFD model. These are listed below, each is employed to reduce the number of cells required. As part of the modelling process the significance of each of these assumptions will be investigated to verify the simplifications are valid.

Geometry Assumptions:

- Exciter airgap is neglected - this will reduce the aerodynamic torque on the shaft by a small amount. However, the relative size of the exciter compared to the main rotor determines that it is negligible

- Stator end-windings are simplified by assuming the spaces between windings leaving the stator are neglected as the majority of this space is filled with excess slot liner

- Windings are modelled as bulk solid regions in all areas as they are randomly wound during manufacture. Therefore any attempt to model these individually would only be appropriate for one machine.

- Grilles over the outlets are not modelled as an experimental case that matches this is utilised. A case investigating the inclusion of the model of the room around the generator found there to be a negligible effect on the flow.

- The airgap is considered to have uniform spacing between rotor poles and stator. In reality there is a small grading in the airgap

\section{Experimental Results and CFD validation}

The key experimental data for validation of the CFD model includes shaft torque and mass flow of air through the machine at a range of shaft speeds. 
A matrix of experimental tests has been carried out, all without electrical load on the generator. The tests have included the rotation of the generator in both directions, an investigation on the effects of grilles over outlets, the effect of closing outlets and a completely throttled case where both inlets and outlets were blocked. This combination of tests has provided insight into the impact of inlet and outlet configurations at a range of shaft speeds on both torque and mass flow rate through the machine. This has been used to validate the CFD model as described below.

Figure 5 shows two experimental cases, one with grilles present over the outlets and one without, and the CFD results across a range of shaft speeds. It is clear from Figure 5 that the grilles restrict the air flow rate through the machine. By removing the grilles, $10.4 \%$ more mass flow rate at full speed may be obtained with an increase of $7.8 \%$ torque (see also Figure 6 ). The CFD results in Figure 5 clearly predict the trend of mass flow rate and only under predict the experimental mass flow rate at the greatest point by $4 \%$ at synchronous speed. This is considered a good match between CFD and experimental data and sufficient to validate the approach to modelling the mass flow rate.

Figure 6 presents the experimental validation of the CFD torque results. Experimental 'Case 1' has the main rotor field winding left connected to the exciter rotor with a resulting current flow due to residual magnetism in the exciter. 'Case 2' has the main rotor windings disconnected and open-circuited which provides a more similar comparison to the CFD. The base value for normalisation for Figure 6 is taken as the steady-state torque once the bearings warm up.

Open-circuiting the rotor windings reduces the experimental torque by $9 \%$ providing more accurate validation of the CFD. An unknown small residual magnetism will remain in the rotor laminations. During the processing of experimental data, the bearing torque is estimated as described in the experimental methodology section (2) above. The bearing torque is currently modelled using a simplistic model and this introduces an error into the processed experimental data. For this reason future plans include capturing measured bearing torque data across a range of shaft speeds.

Figure 6 shows that the CFD under predicts the 'Case 2' experimental torque, after allowing for estimated bearing losses, by $7 \%$ at synchronous speed. The significance of losses due to windage, bearings and current from the exciter to rotor is shown and the trend in torque with increasing shaft speed is clearly captured. The accuracy of the CFD prediction of torque is considered sufficient to further validate the airflow modelling.

\section{Machine Design Conclusions}

Results at synchronous speed and their validation are of the greatest importance. However, by running experimental tests and CFD cases at a range of speeds, trends can be matched which is very important to show the physics is correctly being modelled. Trends in the machine's airflow behaviour also allow a greater understanding of whether components' share of windage alters through the speed range. 
The flow paths through the machine are monitored using interior surface patches. Interior surfaces are created over the drive and non-drive end of the airgap and interpolar regions as well as at the non-drive end in the stator channels between the stator and casing (see Figure 4).

Flow in and out of the machine is also monitored through the inlet and outlet boundaries. Across the speed range, a nearly constant $32 \%$ of flow passes through the airgap and interpolar regions with the remainder passing around the back of the stator. Both inlets are located on the lower half of the machine opposite each other (see Figure 1 and Figure 2). Around 12\% more air flows in through the inlet whose inflow joins the direction of rotation. Only around $12 \%$ of the air which passes in between the rotor and stator enters through the airgap even though it contributes to $17 \%$ of the area in this region (see Figure 4). The rest enters through the larger interpolar spaces. Around $35 \%$ of the mass flow through the front of the airgap falls into the interpolar spaces by the time it reaches the rear of the airgap increasing their flow by around 5\% each (see Figure 4). 90\% of the flow leaves through the outlets whose normal are aligned to the tangential direction of rotation. This suggests that the other outlets are poorly located. This, however, is emphasised due to the pressure outlet normal outflow condition mentioned earlier. CFD results allow the total airflow related windage torque to be identified. The windage due to the fluid may be broken down to pressure and viscous components and these can be further broken down by each important geometry feature. Pressure torque contributes the majority of the total torque over the speed range investigated with a mean value of $97.8 \%$ of the total torque with a standard deviation of $0.3 \%$. This suggests that there might be very little in the way of improvement in machine efficiency associated with any improvements made to the viscous related properties of the machine such as surface roughness. As would be expected, the key region for the viscous dependent torque on the rotating parts is the rotor (see Figure 7), due to the high gradients of shear stress experienced in the airgap. However this equates to only around $1.2 \%$ of the entire windage torque, suggesting it is not worth focussing too much attention on improving this aspect of the machine. The viscous torque contributions for other components are negligible also (see Figure 7). The exciter airgap is not being modelled here to reduce computational expense. This means its viscous torque contribution is under predicted. However, this is a reasonable assumption since the exciter is shorter than the rotor which is considered negligible so any exciter viscous losses would too be negligible.

The contribution of each component to the pressure torque is steady through the investigated speed range (see Figure 8). The fan is the most significant contributor to the more important pressure component of the torque on the rotating parts (see Figure 8). This is considerably higher than the rotor part. If a reduction of flow could be achieved with minimal effect on the thermal performance of the machine, these results suggest fan design is the key region for airflow related efficiency gains.

\section{Conclusions}


A full $360^{\circ}$ airflow model of a synchronous machine has been successfully created and experimentally validated. At synchronous speed the experimentally tested mass flow rate was under predicted by $4 \%$ by the CFD. The torque was under predicted by $7 \%$. The windage torque is more difficult to accurately quantify due to the inclusion of bearing losses and residual magnetism in the rotor laminations in the experimental data. Recording experimental torque data with rotor windings open circuited is essential to remove the $9 \%$ of the torque this contributes.

Inclusion of the room around the generator reduces the difference to experimental data to $1.5 \%$ and $28 \%$ for mass flow rate and torque respectively. Although these results provide a closer match to experimental data, the cost of $11 \%$ more cells in the model is considered too significant a computational expense for the improvement in predictions.

Analysing the CFD torque results showed that the pressure component of torque was $98 \%$, with the viscous component responsible for the small remainder. These results suggest that there is little point in targeting viscous associated properties of the machine, such as surface roughness for reducing windage, even on the rotor pole surfaces which account for approximately $60 \%$ of the viscous torque.

The fan is by far the most significant component related to windage. It consumes $87 \%$ of the total windage torque from the machine. Aerodynamic only improvements should be targeted at the fan design based on these results.

Care must be taken not to segregate these findings from thermal analysis as they are both intrinsically linked.

It is intended that the airflow modelling shown will be developed and include a full conjugate heat transfer analysis of the machine. This will provide a better understanding of thermal management within the machine and allow improvements to be proposed. Further specific airflow modelling will look at the effect of transient flow using 'Fluent's sliding mesh model'[22]. Zones around inlets/outlets will be created to ensure accurate modelling at the lowest computational expense. Bearing losses from the experimental results will be investigated further to improve their modelling with experimental testing of bearing losses investigated. Local fluid velocities will be experimentally tested between the stator barrel and casing to further validate the airflow CFD modelling. Detailed modelling of the grilles will be evaluated in future models.

\section{Acknowledgements}

The support of Cummins Generator Technologies and EPSRC is gratefully acknowledged for the research presented in this paper.

\section{References}

1. Hughes A. Electric Motros and Drives2006.

2. Maynes BDJ, Kee RJ, Tindall CE, Kenny RG. Simulation of airflow and heat transfer in small alternators using CFD. Iee Proceedings-Electric Power Applications. 2003 Mar;150(2):146-52.

3. Okoro OI, Agu MU, Chinkuni E. Basic Principles and Functions of Electrical Machines. The Pacific Journal of Science and Technology. 2006 May 2006;7(1):45-52.

4. Hay N, Lampard D, Pickering SJ, Roylance TF. Convection Heat Transfer Correlations Relevant to Cooling Situations in Electric Motors. ASME Winter Annual Meeting, New Orleans, Louisiana. 1993:8. 
5. Staton DA, Pickering SJ, Lampard D. Recent Advancements in the Thermal Design of Electric Motors. Presented at the SMMA 2001 Fall Technical Conference "Emerging Technologies for Electric Motion Industry", Durham, North Carolina, USA. 2001 3-5 Oct. p.1-11.

6. Boglietti A, Cavagnino A, Staton D, Shanel M, Mueller M, Mejuto C. Evolution and Modern Approaches for Thermal Analysis of Electrical Machines. IEEE Transactions on Industrial Electronics. 2009 Mar;56(3):871-82.

7. Dajaku G, Gerling D. An improved lumped parameter thermal model for electrical machines. 17th International Conference on Electrical Machines (ICEM 2006). September 2-5, 2006.

8. Gilson GM, Pickering SJ, Hann DB, Gerada C. Analysis of the End Winding Heat Transfer variation with Altitude in Electric Motors. Industrial Electronics, 2009 IECON '09 35th Annual Conference of IEEE Porto2009. p. 2545 - 50.

9. Gilson GM, Raminosoa T, Pickering SJ, Gerada C, Hann DB. A Combined Electromagnetic and Thermal Optimisation of an Aerospace Electric Motor. International Conference on Electrical Machines (ICEM). 6-8 Sept 2010.

10. Boglietti A, Cavagnino A, Staton D. Determination of critical parameters in electrical machine thermal models. Ieee Transactions on Industry Applications. 2008 Jul-Aug;44(4):1150-9.

11. Boglietti A, Cavagnino A, Staton DA, Popescu M. Experimental assessment of end region cooling arrangements in induction motor endwindings. Iet Electric Power Applications. 2011 Feb;5(2):203-9.

12. Wrobel R, Mellor PH, McNeill N, Staton DA. Thermal Performance of an Open-Slot Modular-Wound Machine With External Rotor. Ieee Transactions on Energy Conversion. 2010 Jun;25(2):403-11.

13. Mejuto C, Mueller M, Shanel M, Mebarki A, Reekie M, Staton D. Improved Synchronous Machine Thermal Modelling. Icem: 2008 International Conference on Electrical Machines, Vols 1- 4. 2009:367-72 2409.

14. Mei W, Jabbar MA, Tay AAO. Determination of thermal performance of small electric motors. IEEE. 2001.

15. Micallef C, Pickering SJ, Simmons KA, Bradley KJ. Improved Cooling in the End Region of a Strip-Wound Totally Enclosed Fan-Cooled Induction Electric Machine. IEEE Transactions on Industrial Electronics. 2008 Oct;55(10):3517-24.

16. Chang C-C, Cheng C-H, Ke M-T, Chen S-L. Experimental and Numerical Investigations of Air Cooling for a LargeScale Motor. International Journal of Rotating Machinery. 2009;2009:1-7.

17. Pickering SJ, Lampard D, Shanel M. Ventilation and heat transfer in a symmetrically ventilated salient pole synchronous machine. International Conference on Power Electronics, Machines and Drives. 2002(487):462-7 661.

18. Micallef C. End Winding Cooling in Electrical Machines [PhD Thesis]: University of Nottingham; 2006.

19. Howey DA, Holmes AS, Pullen KR. Measurement and CFD Prediction of Heat Transfer in Air-Cooled Disc-Type Electrical Machines. Ieee Transactions on Industry Applications. 2011 Jul-Aug;47(4):1716-23.

20. Kleine S, McClintock FA. Descibing uncertainties in single-sample experiments. Mechanical Engineering. 1953:3-8.

21. http://www.skf.com. Accessed March 2012.

22. Ansys. Fluent User Manual.

23. Shanel M. Investigation of Rotor Cooling in Salient Pole Electrical Machines [PhD Thesis]2002. 


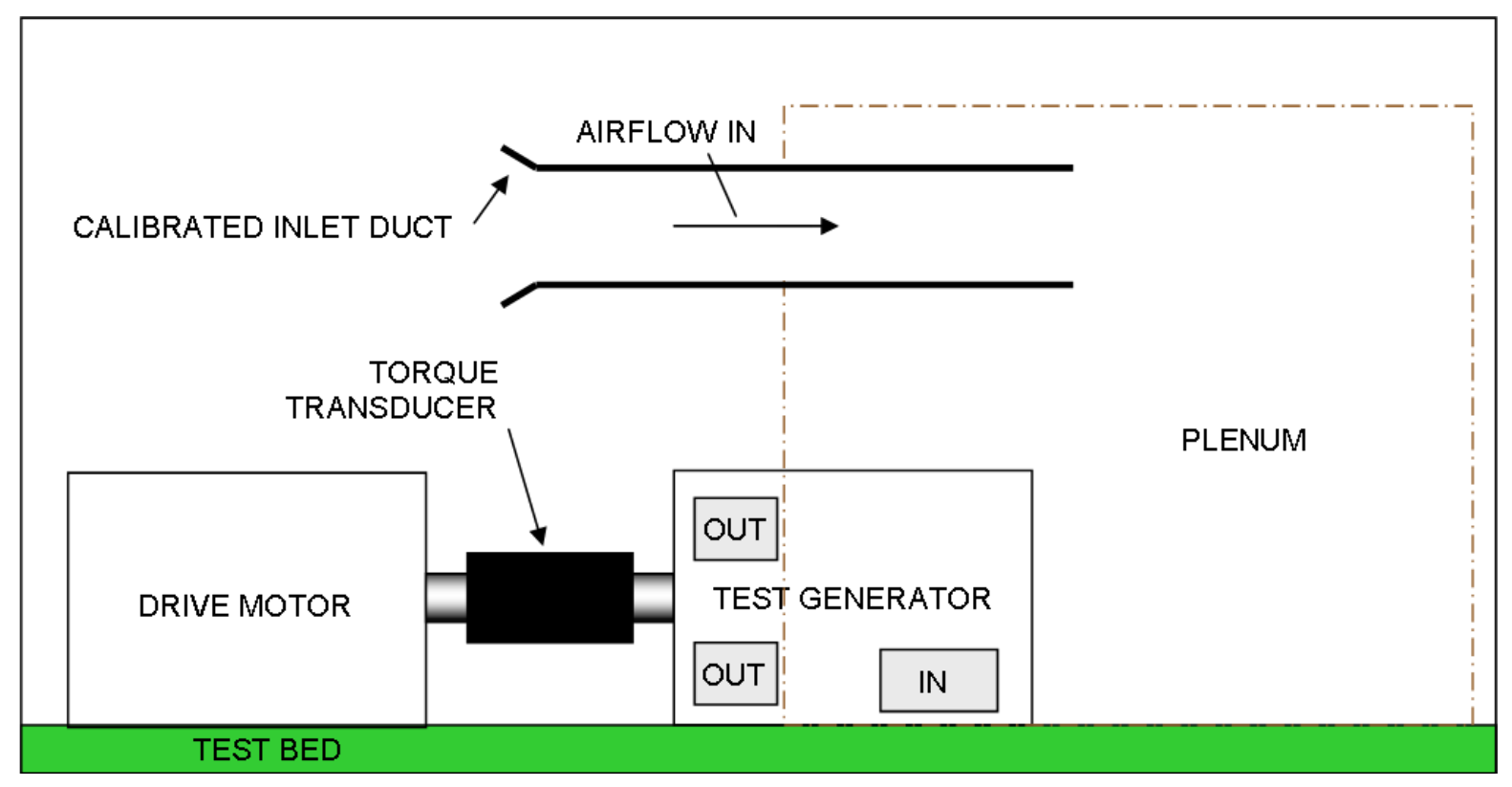

Figure 1: Schematic of Experimental Rig

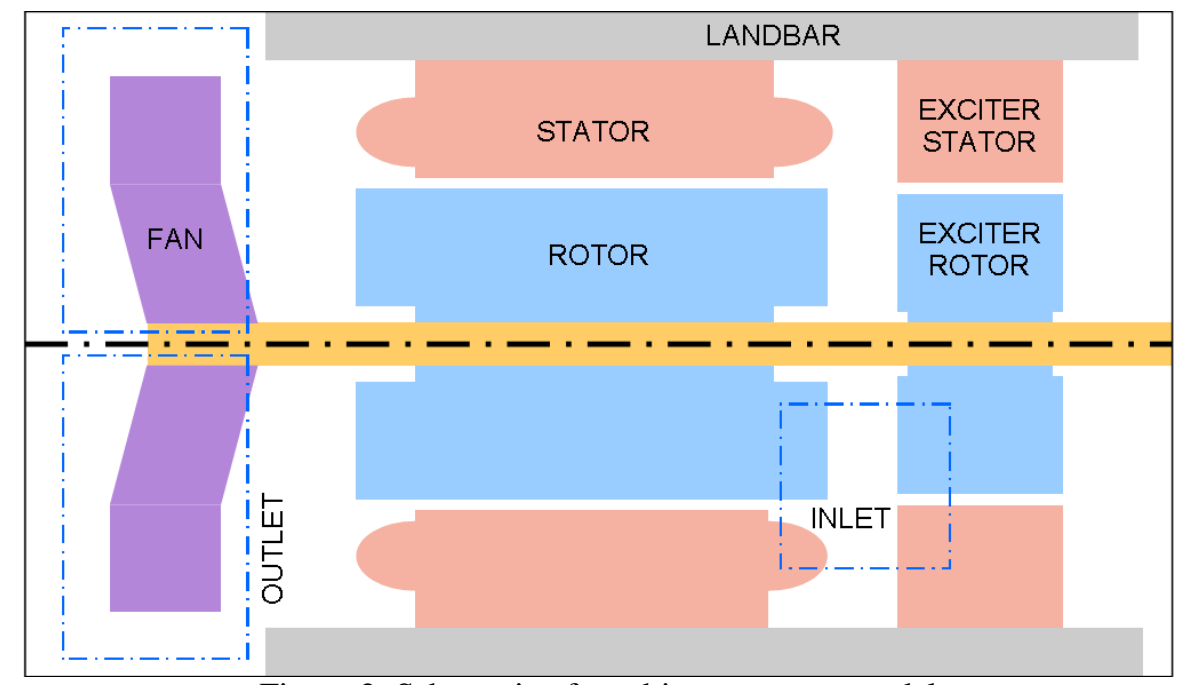

Figure 2: Schematic of machine geometry model 


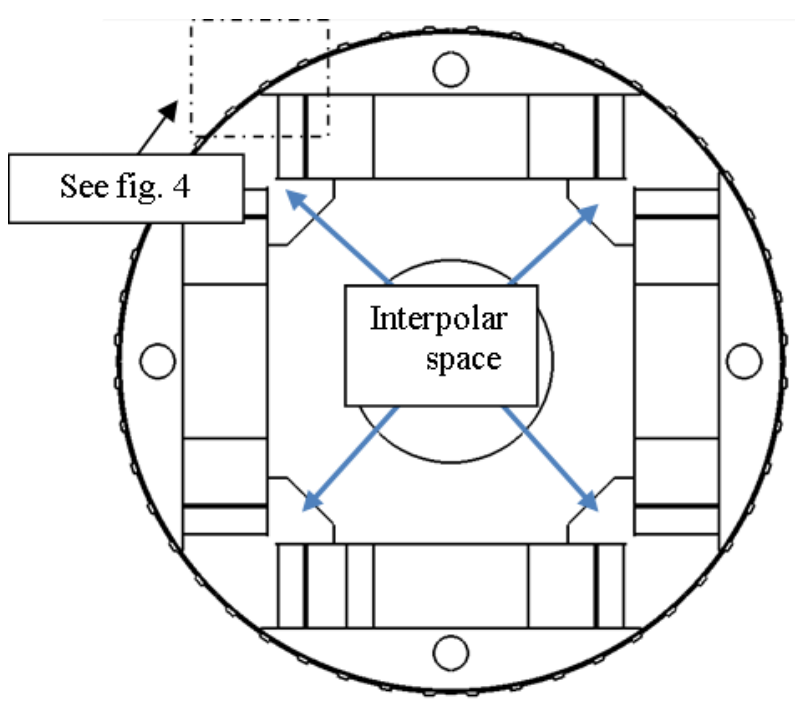

Figure 3: Interior surface labels of the interpolar spaces shown on a midway axial plane through generator

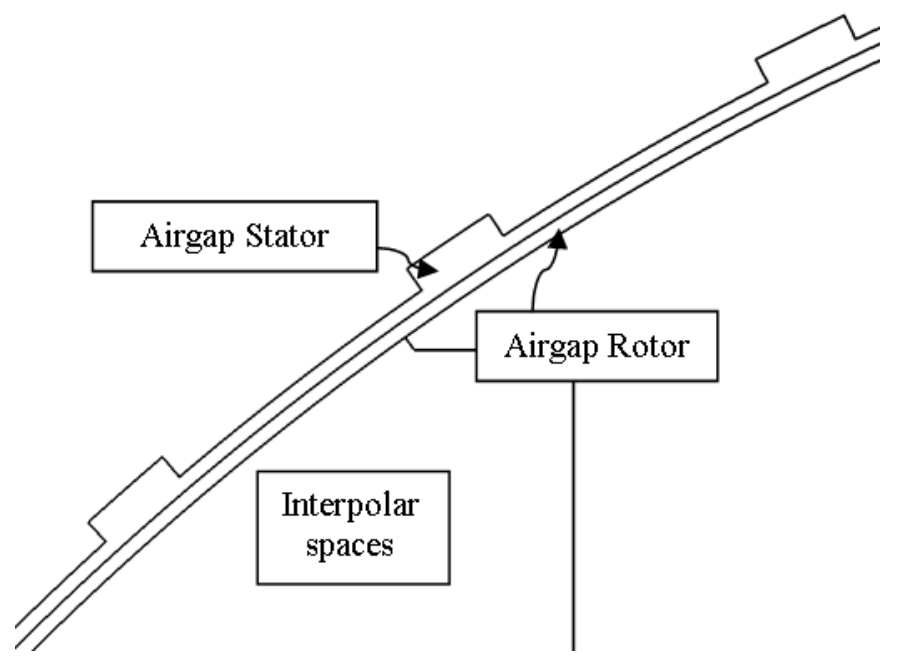

Figure 4: Interior surface labels of the airgap shown on a midway axial plane through generator 


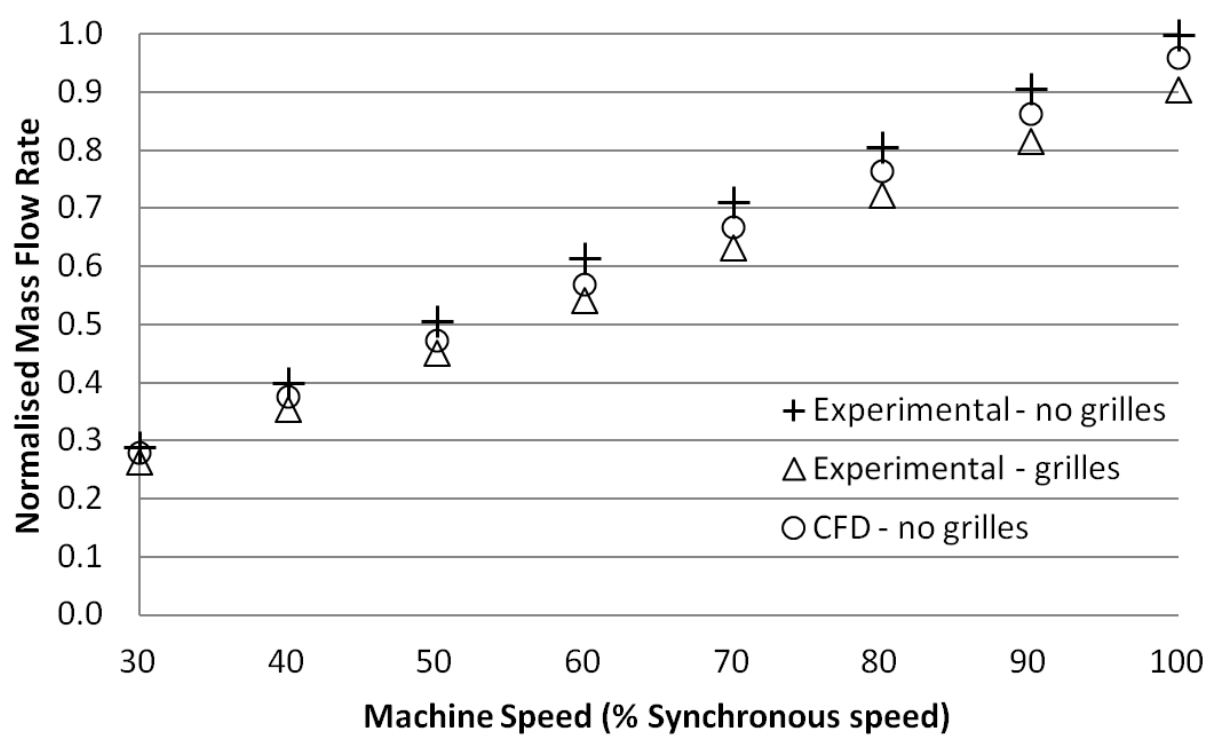

Figure 5: A graph to show the effect of grilles on mass flow rate and the validation of CFD results without grilles

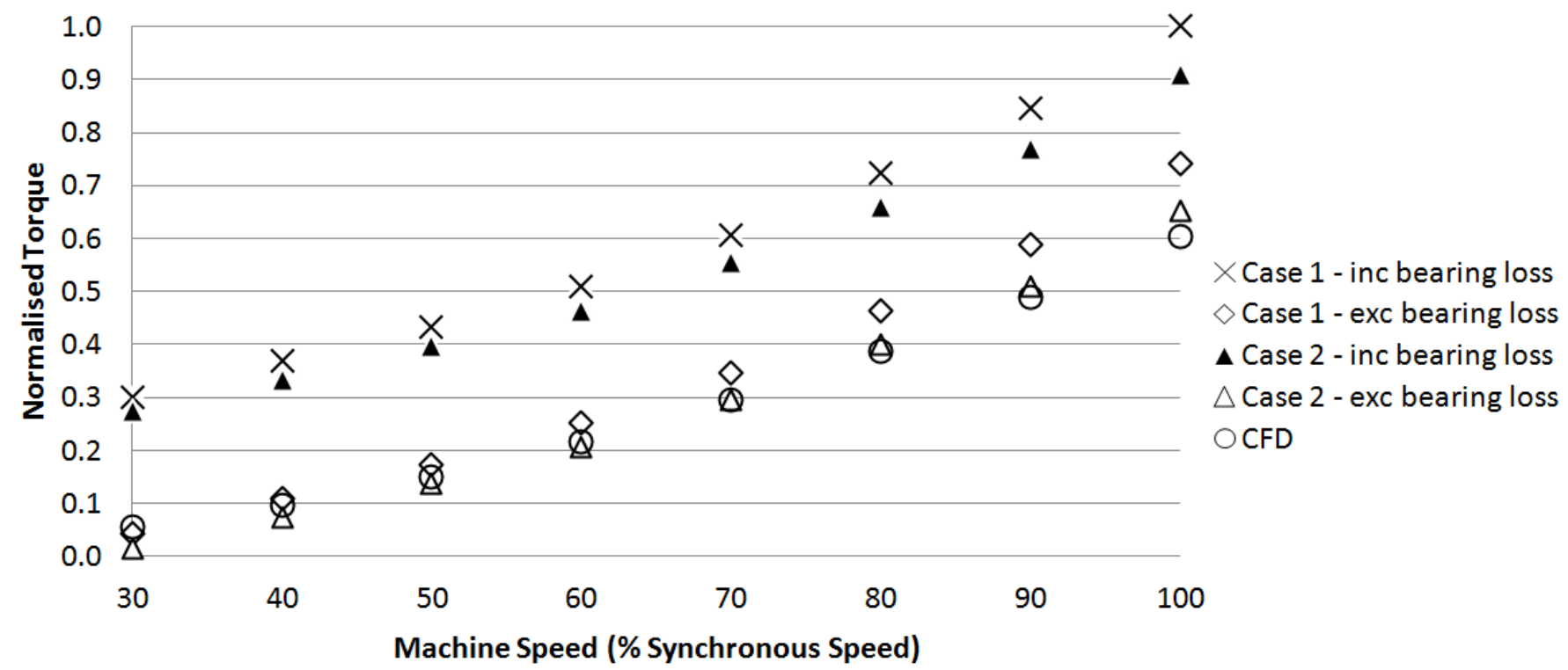

Figure 6: A graph to show the validation of CFD torque results using experimental data

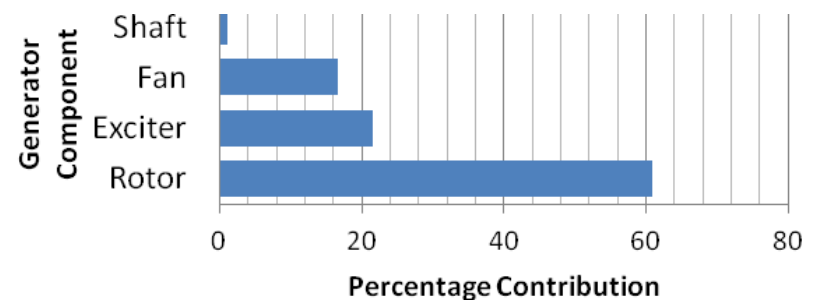

Figure 7: Percentage contribution to the viscous torque by generator component 


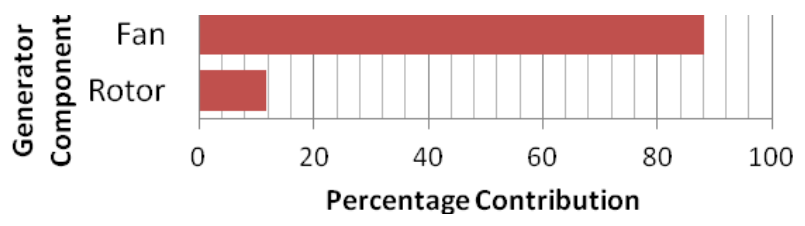

Figure 8: Percentage contribution to the pressure torque by generator component 